Supplement of Nat. Hazards Earth Syst. Sci., 15, 1757-1761, 2015

http://www.nat-hazards-earth-syst-sci.net/15/1757/2015/

doi:10.5194/nhess-15-1757-2015-supplement

(C) Author(s) 2015. CC Attribution 3.0 License.

(c) (1)

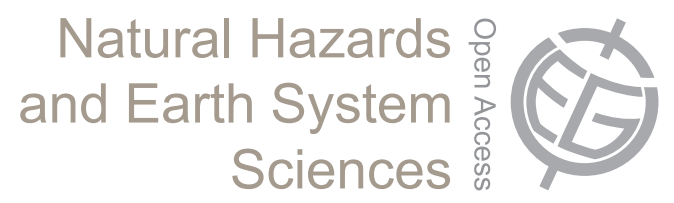

Supplement of

Statistical detection and modeling of the over-dispersion of winter storm occurrence

\title{
M. Raschke
}

Correspondence to: M. Raschke (mathiasraschke@t-online.de)

The copyright of individual parts of the supplement might differ from the CC-BY 3.0 licence. 


\section{a. Thinning and over-dispersion}

7

The survival probability that a storm event of a sample with given return period $\mathrm{CRP}_{\text {old }}$ is 8 also member of the sample with $\mathrm{CRP}_{\text {new }}$, being $\mathrm{CRP}_{\text {old }}>\mathrm{CRP}_{\text {new }}$, is $P_{\text {survival }}=\mathrm{CRP}_{\text {old }} / \mathrm{CRP}_{\text {new }}$.

9 Following to Ross (2007, Example 3.16 and 3.18), the expectation and variance of the new

10 count variable $X_{\text {new }}$ is

$11 E\left(X_{\text {new }}\right)=E\left(\sum_{i=1}^{X_{\text {old }}} I_{\text {new }, i}\right)=E\left(X_{\text {old }}\right) E\left(I_{\text {new }}\right)$ and

$12 V\left(X_{\text {new }}\right)=V\left(\sum_{i=1}^{X_{\text {old }}} I_{\text {new }, i}\right)=E\left(X_{\text {old }}\right) V\left(I_{\text {new }}\right)+V\left(X_{\text {old }}\right) E\left(I_{\text {new }}\right)^{2}$.

13 The binary random variable $I_{\text {new }, i}$ describes whether the storm event $i$ is member of the new 14 return level with $I_{\text {new }, i}=1$ or if it is thinned out with $I_{\text {new }, 1}=0$. We can also declare $I_{\text {old }}$ for the 15 old sample, but there is only one kind of realization with $I_{\text {old }}=1$ being considered here. Figure 16 A1 illustrates the thinning out.

17 The random variable $I_{\text {new }}$ is Bernoulli distributed with expectation $E(I)$ and variance $V(I)$

$18 E(I)=P_{\text {survival }}$ and

$19 V(I)=P_{\text {survival }}\left(1-P_{\text {survival }}\right)$.

20 Now I introduce the relation

$21 V\left(X_{\text {old }}\right)=E\left(X_{\text {old }}\right)+\beta E\left(X_{\text {old }}\right)^{2}$

22 Where the over-dispersion parameter $\beta>0$, which is determined by variance and expectation 23 of count variable $X_{\text {old }}$. Eq. (A2) is modified for the new count variable with Eq. (A3,A4) to

$24 V\left(X_{\text {new }}\right)=E\left(X_{\text {old }}\right) P_{\text {survival }}\left(1-P_{\text {survival }}\right)+E\left(X_{\text {old }}\right) P_{\text {survival }}^{2}$. 
1 This equation can be simplified as follows:

$2 V\left(X_{\text {new }}\right)=E\left(X_{\text {old }}\right) P_{\text {survival }}+\beta E\left(X_{\text {old }}\right)^{2} P_{\text {survival }}^{2}$,

3 wherein $E\left(X_{\text {old }}\right) P_{\text {survival }}$ is replaced by $E\left(X_{\text {new }}\right)$ according to Eq. $(1,3)$ and we get

$4 \quad V\left(X_{\text {new }}\right)=E\left(X_{\text {new }}\right)+\beta E\left(X_{\text {new }}\right)^{2}$.

5 The resulting Eq.(A8) is basically equal to Eq.(A5). Therefore, Eq. (A5) is universal and

6 applies to $X_{\text {old }}$ and $X_{\text {new }}$. This is not a totally new inference, as it was already derived for other

7 purposes (e.g., Mack 2002). I want to stress the fact that these results apply if the storm events

8 are independent from each other and occur in time according to an inhomogeneous Poisson

9 process. Eq.(A5,A8) can be proven by simple Monte Carlo simulations (not shown).
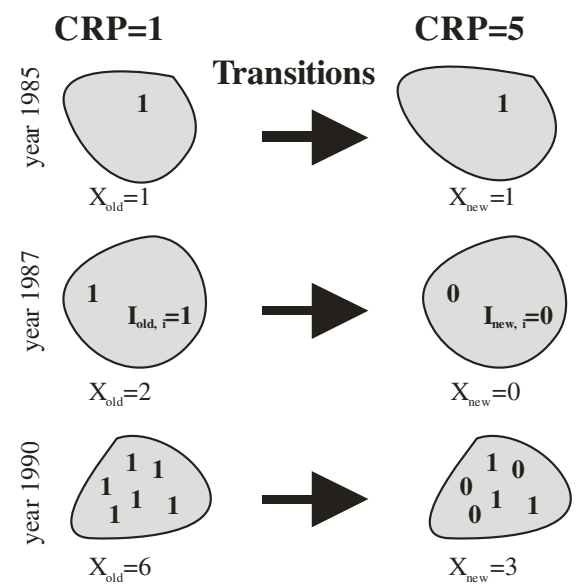

11 Figure A1: Transition of the count variable $X$ of number of storms per season and the 12 corresponding binary variable $I$. The examples are for observations of the DWD samples 13 (Karremann 2014, Fig. 3).

\section{b. The storm samples}

Table B1: Analysed samples; the data DWD, NCEP and ERAI of historic storms are from

16 Karremeann et al. (2014; Fig. 2 and supplementary Tab. B1)

\begin{tabular}{|c|c|c|c|c|c|c|c|c|c|c|c|c|c|}
\hline \multirow{2}{*}{\multicolumn{2}{|c|}{$\begin{array}{c}\text { Sample type } \\
\text { Considered return } \\
\text { period (CRP) [a] }\end{array}$}} & \multicolumn{3}{|c|}{ DWD } & \multicolumn{3}{|c|}{ NCEP } & \multicolumn{3}{|c|}{ ERAI } & \multicolumn{3}{|c|}{ GMC corr } \\
\hline & & 1 & 2 & 5 & 1 & 2 & 5 & 1 & 2 & 5 & 1 & 2 & 5 \\
\hline \multirow{8}{*}{ 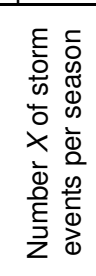 } & 0 & 14 & 21 & 26 & 12 & 19 & 26 & 12 & 18 & 25 & 1734 & 2593 & 3378 \\
\hline & 1 & 8 & 6 & 3 & 9 & 8 & 3 & 10 & 10 & 4 & 1258 & 1065 & 621 \\
\hline & 2 & 6 & 2 & 0 & 7 & 2 & 0 & 6 & 1 & 1 & 666 & 341 & 84 \\
\hline & 3 & 0 & 0 & 1 & 1 & 1 & 1 & 0 & 1 & 0 & 286 & 78 & 8 \\
\hline & 4 & 1 & 0 & 0 & 1 & 0 & 0 & 2 & 0 & 0 & 108 & 10 & 0 \\
\hline & 5 & 0 & 1 & 0 & 0 & 0 & 0 & 0 & 0 & 0 & 30 & 5 & 1 \\
\hline & 6 & 1 & 0 & 0 & 0 & 0 & 0 & 0 & 0 & 0 & 8 & 0 & 0 \\
\hline & 7 & 0 & 0 & 0 & 0 & 0 & 0 & 0 & 0 & 0 & 2 & 0 & 0 \\
\hline
\end{tabular}

References see brief communication. 